\title{
Factors Predictive of Medical Student Involvement in Research: Results from a New Zealand Institution
}

This article was published in the following Dove Press journal:

Advances in Medical Education and Practice

\author{
Yassar Alamri $\mathbb{D}^{\prime}$ \\ Erik Monasterio ${ }^{2}$ \\ Tim J Wilkinson (D) ${ }^{1,3}$ \\ 'Department of Medicine, University of \\ Otago, Christchurch, New Zealand; \\ 2Department of Psychological Medicine, \\ Canterbury District Health Board, \\ Christchurch, New Zealand; ${ }^{3}$ Medical \\ Education Unit, University of Otago, \\ Christchurch, New Zealand
}

Background: Previous studies have elucidated several benefits of engagement in research by medical students. The aim of the current study was to assess if any factors influenced the student's actual involvement (not mere interest) in scholarly activities during medical school. Methods: All medical students at the University of Otago were invited via e-mail to complete an online questionnaire. The outcome was a substantial contribution to a research project. The predictors were prior research experience, student's entry route, and planned career type. Multiple regression analysis was undertaken to control for any confounding factors influencing medical students' involvement in research.

Results: Valid responses were gathered from 669 students (yielding a response rate of $44.8 \%)$. Of those, 254 students $(38.3 \%)$ had engaged in one or more research activities. Students who engaged in research activities indicated a higher likelihood of future involvement in research but expressed less interest in internal medicine sub-specialties as potential future careers.

Conclusion: A sizeable proportion of our samples has been involved in the research. Targeting medical students not yet involved in research may necessitate additional curricular and faculty support in order to stimulate their research curiosity.

Keywords: medical education and training, New Zealand, medical student

\section{Introduction}

Previous studies have elucidated several benefits of engagement in research by medical students. These include improved personal academic fulfilment, ${ }^{1}$ cultivating critical thinking, ${ }^{2}$ sharpening the ability to critique an ever-evolving medical literature, ${ }^{3}$ and a higher likelihood of future career and success in research and academia. ${ }^{4}$

Despite these putative benefits, however, engagement in research activities by medical students remains mediocre at best. ${ }^{5}$ Furthermore, New Zealand medical students were reported to be among the least aware of research opportunities in a recent survey of medical students from several countries. ${ }^{6}$

In order to bolster early research engagement by medical students, investigating factors that foster scholarly curiosity (and promote or hinder engagement in research activities) ought to be undertaken. Several studies have cited time and financial constraints as the factors to blame. ${ }^{5,7}$ However, demonstrating the realworld benefit of providing these two precious commodities has been challenging. For example, providing medical residents with "protected research-time" did not result in greater research productivity. ${ }^{8}$ In addition, "luring" residents with
Correspondence: Yassar Alamri

Canterbury District Health Board, 2

Riccarton Avenue, Christchurch, 801 I,

New Zealand

Tel +6421750015

Fax +6433786080

Email yassar.alamri@nzbri.org
Advances in Medical Education and Practice 2021:12 183-187

DovePress in $\square$ 
monetary rewards for research activities has only led to an increase in low-quality research (eg, targeting case reports), ${ }^{9}$ and has been criticised for fuelling an "external reward mentality"10 rather than igniting an intrinsically curious and motivated mind.

At our institution, medical students are given the opportunity to undertake formalised research as part of 10week summer studentships, or an intercalated research degree (BMedSc(Hons) or $\mathrm{PhD}) .{ }^{11}$ The medical course itself is a six-year programme: the first-year is common to all health-sciences students; years 2 and 3 focus on basic sciences (ie, pre-clinical phase); and years 4, 5 and 6 focus on clinical experience. Students may enter the medical course after high-school (ie, under-graduate entry), or, less commonly, after the completion of another degree (ie, post-graduate entry). ${ }^{11}$

We have previously examined factors associated with an interest in research involvement among pre-clinical medical students in New Zealand. ${ }^{1}$ Contrary to our preconceived hypotheses, older age at matriculation (representing a "time pressure"), and higher debt (representing a "financial pressure") did not influence the student's interest in being involved in research activities. Defining the characteristics of students who make the leap from "being interested in" to "doing" research would help fill an important gap in our current knowledge. The aim of the current study, therefore, was to assess if any factors influenced the student's actual involvement (not mere interest) in scholarly activities during medical school.

\section{Methods}

\section{Study Setting and Participants}

The present study is part of a programme of medical education research conducted at the University of Otago, Christchurch. ${ }^{12}$ For the current study, all medical students at the University of Otago were invited via their University e-mail to complete an online questionnaire. The study ran over a 15-week period (March-July 2019), with three-weekly reminders. The project was approved by the University of Otago Human Ethics Committee (reference D18/207).

\section{Definitions}

Involvement in research was defined as a substantial contribution (as defined by the International Committee of Medical Journal Editors $^{13}$ ) to a research project by a medical student. The research project could have been in the form of summer studentships, clinical audits/ research, journal publications, or conference oral/poster presentations. Mandatory curricular research modules and research degrees obtained prior to medical school matriculation were excluded.

\section{Study Questionnaire}

The questionnaire was developed by the lead author, in consultation with the co-authors, as well as previously published literature. ${ }^{1,14}$ It was electronically administered via SurveyMonkey ${ }^{\text {TM }}$. Students were asked about their demographics (age, and sex), previous and future intended careers (eg, medical school entry route, intended specialty of choice, and planned career type), and prior research experience (including prior research degrees, and research projects during medical school).

\section{Statistical Analysis}

Descriptive statistics were utilised to present most of the data (expressed as means $\pm \mathrm{SD}$, medians, or proportions). Inferential comparisons were made with Chi-square test (for categorical data), and two-sided Student's $t$-test (for continuous data). Logistic regression analysis was undertaken to control for any confounding factors influencing medical students' involvement in research. All analyses were undertaken using SPSS Statistics ${ }^{\circledR}$ software package (version 25.0.0.0).

\section{Results \\ Study Sample}

Of the contacted 1,493 medical students, 669 students returned the completed surveys (yielding a response rate of $44.8 \%$ ). More than two thirds of the respondents $(67.6 \%)$ were female. The median age was 22 years (range, 18-52). The respondents were made up of 252 preclinical medical students $(37.7 \%), 325$ clinical medical students $(48.6 \%)$, and 11 intercalating students (1.6\%); 81 medical students $(12.1 \%)$ did not indicate their current level of training.

\section{Research Involvement}

Of the respondents, 254 students $(38.3 \%)$ had engaged in one or more research activities. Of those students, 149 students $(58.7 \%)$ were involved in a single research project, 87 students $(34.3 \%)$ in two or three projects, and 18 students $(7.1 \%)$ in four or more projects. Among junior medical students (ie, years 2 and 3), 15.7\% had participants in one 
Table I Univariate Analyses of Study Respondents

\begin{tabular}{|l|l|l|l|}
\hline & \multicolumn{1}{|c|}{ RI } & \multicolumn{1}{|l|}{ Non-RI } & P-value \\
\hline N & 191 & $3 I I$ & \\
Age (years; mean \pm SD) & $23.4( \pm 3.4)$ & $22.3( \pm 10.6)$ & 0.04 \\
European ethnicity (\%) & $63.6 \%$ & $60.8 \%$ & 0.35 \\
Internal medicine and sub-specialties as first choice (\%) & $32 \%$ & $68 \%$ & 0.02 \\
Surgery as first choice (\%) & $44 \%$ & $56 \%$ & 0.08 \\
General practice as first choice (\%) & $29 \%$ & $29 \%$ & 0.11 \\
Psychiatry as first choice (\%) & $3.2 \%$ & $6.5 \%$ & 0.14 \\
\hline
\end{tabular}

Abbreviation: RI, medical students involved in research activities.

or more research activities. This proportion rose to $56 \%$ among senior medical students (ie, years 4, 5 and 6).

\section{Student Characteristics}

Students who were involved in research activities (RI) were older than students without research involvement (non-RI; mean $23.7 \pm 3.34$ years vs $21.8 \pm 3.5$ years, respectively; $p<0.001)$. However, this is not surprising as a higher proportion of RI students $(81 \%)$ were more senior medical students than non-RI $(40 \%)$ students $(\mathrm{p}<$ 0.001). The sex distribution was similar between the RI and non-RI students (male $32.7 \%$ vs $32.3 \%$, respectively; $p=0.9)$. The ethnic make-up of the two groups was not statistically different (see Table 1).

\section{Factors Predictive of Research Involvement}

A step-wise logistic regression analysis was undertaken to create a model with the best fit. We adjusted for several confounding factors that would affect a student's involvement in research (Table 2); these included the student's age, intended specialty of choice, and planned career type (ie, academic vs full-time clinical). Because of collinearity between student entry (undergraduate vs post-graduate) and age, we chose to enter age into the model. Medical students were more likely to be involved in research if they indicated a future intention to remain engaged (at $\geq 0.1$ fulltime-equivalent) in research activities $(\mathrm{OR}=2.99$, $p<0.001)$. In contrast, they were less likely to undertake research activities if they chose Internal Medicine (compared with Surgery, General Practice, and Psychiatry) as a career choice $(\mathrm{OR}=0.62, p=0.02)$.

\section{Discussion}

The present study has provided several insights into the characteristics of students who are involved in research activities during medical school. A sizeable number of responses were collected for this study. RI students were more likely to be senior medical students, presumably reflecting a greater opportunity to be involved in research activities (eg, clinical audits or case reports of patients on the ward), and a more complex understanding of the importance of research to clinical practice compared with junior/pre-clinical medical students.

It is difficult to disentangle the effect of social and academic factors (eg, older age, having a prior degree, and future career aspirations) on the motivation to undertake research. A previous study has shown a higher impact of the student's age on their career choice and motivation. ${ }^{15}$ In the present study, RI students indicated a higher likelihood of future involvement in research and academia. Whether this is a cause (ie, students inclined towards academia are more likely to seek early research opportunities) or an effect (ie, students had enjoyed their research experience in medical school, and decided to continue on this career trajectory as a result) is uncertain.

Table 2 Regression Analysis Results Predicting Early Involvement in Research by Medical Students

\begin{tabular}{|l|l|l|l|}
\hline Variable* & $\begin{array}{c}\text { OR (95\% Confidence } \\
\text { Intervals) }\end{array}$ & $\boldsymbol{\beta}$ \\
\hline Age & $1.01(0.98-1.04)$ & 0.01 & 0.53 \\
Interest in research as part of a future career after graduation & $2.99(2.03-4.39)$ & $0.62(0.42-0.91)$ & -0.48 \\
Internal medicine and sub-specialties as first choice & 0.02 & -0.02 & 0.09 \\
\hline
\end{tabular}

Notes: Goodness-for-fit $\mathrm{R}^{2}=0.4 \mathrm{I}$; *ompared with an undergraduate-entry student, planning to pursue general practice, but not interested in future research activities. 
A previous literature review ${ }^{16}$ found post-doctoral medical trainees (ie, having completed a $\mathrm{PhD}$ ) who were intrinsically motivated to undertake research to be more likely to pursue academic careers (therefore, lending support to the former hypothesis above).

Our students who are involved in research expressed a lower interest in internal medicine (and its subspecialties) as future career choices. This may reflect the relative ease of obtaining medical training posts compared with the traditionally more "competitive" surgical residency training posts. ${ }^{17}$ In a recent study, New Zealand medical students who preferred psychiatry and internal medicine specialties were found to be more likely to have undertaken an intercalated $\mathrm{MBChB} / \mathrm{PhD}$ degree (ie, longer and more comprehensive research endeavours). ${ }^{18}$ How these findings could be reconciled in light of the findings of the present study is unclear.

Finally, several limitations of this study are acknowledged. The response rate from the surveyed students was sub-optimal. Nevertheless, the number of respondents was high, and the response rate was typical of that of medical education research. ${ }^{19}$ Specific validation of the study questionnaire was not undertaken, but this was because it was based upon similar "validated" surveys in the current literature. Female respondents made up the majority (67.6\%) - a proportion that is higher than the general make-up of medical students in New Zealand (58\% female in $2018^{20}$ ). Whether this affects the results of the current study remains undetermined, however. As the sex distribution between the RI and non-RI students was not statistically different, sex-biased responses on the basis of RI are unlikely to have influenced the response rate. Additionally, this cross-sectional study was not designed to follow the students' career trajectories; a longitudinal study is being planned by our research group. Finally, the sample was self-selected to participate, and was from a single institution in New Zealand; certainly, the distribution of the respondent stages (pre-clinical vs clinical) does not accurately reflect the actual distribution of students across the medical degree. Pursuing a national study of all medical students in New Zealand (or even attempts to include students from Australia) would provide superior generalisability of our findings. It is possible that a larger study might have greater power to detect other predictive factors. Notwithstanding these limitations, however, the present study provides unique insights into student-factors that are predictive of their research involvement at such an early stage of their careers. Indeed, it is the largest study of its kind from New Zealand to date.

\section{Conclusions}

From this large study, several factors associated with research involvement by medical students were found. These students were more likely to be older, indicate a higher likelihood of future involvement in research, but express less interest in internal medicine and subspecialties as potential future careers. Future studies corroborating (or refuting) our findings are needed. Students not falling within the identified RI demographic may require additional curricular and faculty support in order to stimulate their research curiosity. Critical thinking and sophisticated understanding of the research process are essential skills for the twenty-first century clinician.

\section{Data Sharing Statement}

The datasets used and/or analysed during the current study are available from the corresponding author on reasonable request after completion of data publication.

\section{Ethics Approval and Consent to Participate}

This study was approved by the University of Otago Human Ethics Committee (reference D18/207). All participants provided consent on the electronic survey form.

\section{Consent for Publication}

Participants consented to anonymised data publication.

\section{Acknowledgments}

The authors would like to extend their gratitude to the Department of Psychological Medicine, University of Otago, Christchurch, for their financial assistance with participant compensation. The Department had no involvement in the study otherwise.

\section{Author Contributions}

All authors made a significant contribution to the work reported, whether that is in the conception, study design, execution, acquisition of data, analysis and interpretation, or in all these areas; took part in drafting, revising or critically reviewing the article; gave final approval of the version to be published; have agreed on the journal to which the article has been submitted; and agree to be accountable for all aspects of the work. 


\section{Funding}

The authors received financial assistances (NZ \$1,500) from the Department of Psychological Medicine, University of Otago, Christchurch in the form of gift vouchers in order to reimburse participants in our study.

\section{Disclosure}

Yassar Alamri report a grant from the Department of Psychological Medicine, University of Otago, outside the submitted work. The authors report no other conflicts of interest in this work.

\section{References}

1. Alamri Y. Factors influencing decisions to become involved in research: a study of pre-clinical medical students from New Zealand. Med Sci Educ. 2019;29(2):489-492. doi:10.1007/s40670-019-00717-1

2. Laskowitz DT, Drucker RP, Parsonnet J, et al. Engaging students in dedicated research and scholarship during medical school: the long-term experiences at Duke and Stanford. Acad Med. 2010;85:419-428. doi:10.1097/ACM.0b013e3181 ccc77a

3. Parsonnet J, Gruppuso PA, Kanter SL, et al. Required vs elective research and in-depth scholarship programs in the medical student curriculum. Acad Med. 2010;85:405-408.

4. Reinders JJ, Kropmans TJ, Cohen-Schotanus J. Extracurricular research experience of medical students and their scientific output after graduation. Med Educ. 2005;39:237. doi:10.1111/j.13652929.2004.02078.x

5. Pearson S, Ogden K, Warnecke E, Howes F. Research: why aren't more medical students doing it? Australas Med J. 2017;10 (12):1063-1070. doi:10.21767/AMJ.2017.3257

6. Funston G, Piper RJ, Connell C, Foden P, Young AM, O’Neill P. Medical student perceptions of research and research-orientated careers: an international questionnaire study. Med Teach. 2016;38 (10):1041-1048. doi:10.3109/0142159X.2016.1150981

7. Fang D, Meyer RE. Effect of two Howard Hughes Medical Institute research training programs for medical students on the likelihood of pursuing research careers. Acad Med. 2003;78:1271-1280. doi:10.1097/00001888-200312000-00017

8. Temte JL, Hunter PH, Beasley JW. Factors associated with research interest and activity during family practice residency. Fam Med. 1994;26(2):93-97.
9. Chang CW, Mills JC. Effects of a reward system on resident research productivity. JAMA Otolaryngol Head Neck Surg. 2013;139 (12):1285-1290. doi:10.1001/jamaoto.2013.5303

10. Fried MP. Resident, research, and rewards. JAMA Otolaryngol Head Neck Surg. 2014;140(5):479. doi:10.1001/jamaoto.2014.424

11. University of Otago. Faculty of medicine: health sciences first year. 2019. Available from: https://www.otago.ac.nz/hsfy/index.html. Accessed July 17, 2019.

12. Alamri Y, Al-Busaidi I. Gauging research interest among New Zealand senior medical students. Postgrad Med J. 2020;96 (1132):103. doi:10.1136/postgradmedj-2019-136988

13. International Committee of Medical Journal Editors. Defining the role of authors and contributors. 2020. Available from: http://www. icmje.org/recommendations/browse/roles-and-responsibilities/defin ing-the-role-of-authors-and-contributors.html. Accessed June 6, 2020.

14. Boyle SE, Cotton SC, Myint PK, Hold GL. The influence of early research experience in medical school on the decision to intercalate and future career in clinical academia: a questionnaire study. $B M C$ Med Educ. 2017;17(1):245. doi:10.1186/s12909-017-1066-1

15. Wilkinson TJ, Wells JE, Bushnell JA. Are differences between graduates and undergraduates in a medical course due to age or prior degree? Med Educ. 2004;38(11):1141-1146. doi:10.1111/j.13652929.2004.01981.x

16. Ranieri V, Barratt H, Fulop N, Rees G. Factors that influence career progression among postdoctoral clinical academics: a scoping review of the literature. BMJ Open. 2016;6(10):e013523. doi:10.1136/bmjopen-2016-013523

17. Eley DS, Jensen C, Thomas R, Benham H. What will it take? Pathways, time and funding: Australian medical students' perspective on clinician-scientist training. BMC Med Educ. 2017;17(1):242. doi:10.1186/s12909-017-1081-2

18. Alamri Y, Wilkinson TJ. Career outcomes of students of the intercalated MBChB/PhD: experience from New Zealand. $N Z$ Med J. 2020;133(1508):16-23.

19. Cunningham CT, Quan H, Hemmelgarn B, et al. Exploring physician specialist response rates to Web-based surveys. BMC Med Res Methodol. 2015;15:32. doi:10.1186/s12874-015-0016-z

20. Medical Deans Australia and New Zealand(C). Student statistics report: 2017-2018. December, 2018. Available from: https://medical deans.org.au/md/2018/12/2018_Student_Statistics_Report.pdf. Accessed July 24, 2019.

\section{Publish your work in this journal}

Advances in Medical Education and Practice is an international, peerreviewed, open access journal that aims to present and publish research on Medical Education covering medical, dental, nursing and allied health care professional education. The journal covers undergraduate education, postgraduate training and continuing medical education including emerging trends and innovative models linking education, research, and health care services. The manuscript management system is completely online and includes a very quick and fair peer-review system. Visit http://www.dovepress.com/testimonials.php to read real quotes from published authors. 